is naturaleza 


\section{NATURALEZA Y LIBERTAD}

Revista de estudios interdisciplinares

Número 1

Málaga, 2012

Esta revista es accesible on-line en el siguiente portal: http://grupo.us.es/naturalezayl/ 


\section{Naturaleza y Libertad}

Revista de estudios interdisciplinares

Número 1

Directores: Juan Arana, Universidad de Sevilla; Juan José Padial, Universidad de Málaga; Francisco Rodríguez Valls, Universidad de Sevilla.

Secretaria: Avelina Cecilia Lafuente, Universidad de Sevilla.

Consejo de Redacción: José Luis González Quirós, Universidad Juan Carlos I, Madrid; Francisco Soler, Universität Dortmunt / Universidad de Sevilla; Pedro Jesús Teruel. Universidad CEU Cardenal Herrera; Héctor Velázquez, Universidad Panamericana, México.

Consejo Editorial: Mariano Alvarez, Real Academia de Ciencia Morales y Políticas; Allan Franklin, University of Colorado; Michael Heller, Universidad Pontificia de Cracovia; Manfred Stöcker, Universität Bremen; William Stoeger, University of Arizona.

Consejo Asesor: Rafael Andrés Alemañ Berenguer. Universidad M. Hernández de Elche; Juan Ramón Álvarez, Universidad de León; Luciano Espinosa, Universidad de Salamanca; Miguel Espinoza, Université de Strasbourg; José Manuel Giménez Amaya, Universidad de Navarra; Karim Gherab Martín, Urbana University, Illinois; Martín López Corredoira, Instituto Astrofísico de Canarias; Alfredo Marcos, Universidad de Valladolid; Javier Monserrat, Universidad Autónoma de Madrid; Leopoldo Prieto, Colegio Mayor San Pablo, Madrid; Ana Rioja, Universidad Complutense, Madrid. Madrid; José Luis Rodríguez Recio, Universidad Complutense, Madrid; Javier Serrano, TEC Monterrey (México); Hugo Viciana, Université

Paris I; Claudia Vanney, Universidad Austral, Buenos Aires; José Domingo Vilaplana, Huelva.

\section{Redacción y Secretaría:}

Naturaleza y Libertad. Revista de estudios interdisciplinares. Departamento de Filosofía y Lógica. Calle Camilo José Cela s.n. E-41018 Sevilla.

Depósito Legal: MA2112-2012

๔ 954.55.77.57 Fax: 954.55.16.78. E-mail: jarana@us.es

๑ Naturaleza y Libertad. Revista de Filosofía, 2012 


\section{ÍNDICE}

MANIFIESTO

\section{ESTUDIOS}

Rafael Andrés Alemañ Berenguer. Universidad Miguel Hernández de Elche

La relación mente-materia y el monismo neutral.

Fernando García-Cano Lizcano. Ciudad Real

Evolucionismo y utopia de género

Miguel Ángel Herrero. Universidad Politécnica de Madrid

Instrumentalismo y realismo en la física de James C. Maxwell...

Juan Miguel Suay Belenguer. UNED

La mente mecánica.

José Luis Yepes Hita. Universidad de Murcia

Los «Anales de Física» de L.W. Gilbert.

DisCUSIONES

Francisco José Soler Gil. Universidad de Sevilla - T. Universität Dortmund

¿Se puede naturalizar la epistemología?

Antonio Diéguez. Universidad de Málaga

La opción naturalista. Una respuesta a Francisco Soler

Francisco José Soler Gil. Universidad de Sevilla - T. Universität Dortmund

¿Qué menos que un milagro podría salvar la epistemología naturalista? .265

Antonio Diéguez. Universidad de Málaga

Filosofía sin milagros. Comentarios finales a la contrarréplica de Francisco Soler ...273

CRÍTICA DE LIBROS

Pedro Jesús Teruel, Filosofia y ciencia en Hipatia, (Ángel Martínez Sánchez) . 285 Noticias y COMENTARIOS

Miguel Palomo, Universidad de Sevilla

Si no hay cuerpo, no hay mente: una discusión sobre consciencia y libertad. 
Naturaleza y Libertad. Revista de estudios interdisciplinares. Número 1, 2012. ISSN: 2254-9668

\title{
¿QUÉ MENOS QUE UN MILAGRO PODRÍA SALVAR LA EPISTEMOLOGÍA NATURALISTA? RESPUESTA A ANTONio DiÉGUEZ LUCENA
}

\author{
Francisco José Soler Gil \\ Universidad de Sevilla - Technische Universität Dortmund
}

Recibido: 23/10/2011. Aprobado: 17/01/2012.

El profesor Diéguez Lucena ha tenido la amabilidad de replicar a mi artículo: «¿Se puede naturalizar la epistemología?». Me alegro sinceramente por ello. No sólo por la deferencia que supone atender a mis comentarios, sino porque esto le ha dado ocasión para ofrecernos una magnífica panorámica de las distintas formas de naturalismo vigentes (unas más y otras menos) en el pensamiento actual. Además de un nuevo ejemplo de su riguroso, documentado y sólido método argumentativo. Leer su réplica ha sido un auténtico placer, que le agradezco.

En esta breve respuesta final, y antes de cederle la última palabra al autor de «La Evolución del Conocimiento», no quiero volver a repasar ningún detalle del argumento antinaturalista de Plantinga. Pues considero que, con lo expuesto en los dos artículos anteriores ( $\mathrm{y}$ y sobre todo en el propio libro de Diéguez Lucena!), posee ya el lector elementos más que suficientes para formarse su propio juicio sobre este particular. 
Sin embargo, sí que creo oportuno esbozar, aunque sea a grandes rasgos, mi posición acerca del llamado «naturalismo metodológico». No sólo porque parece ser la versión del naturalismo más apreciada por mi interlocutor, sino porque, de no hacerlo, creo que tal vez podría dar lugar a un malentendido acerca de mi propia posición, sobre todo en lo que se refiere a mi modo de entender la ciencia. Además, su réplica gira realmente en torno a este tema. Pues, si no lo he entendido mal, el planteamiento del artículo-réplica de Diéguez Lucena, podría sintetizarse así:

$\mathrm{El}$ argumento de Plantinga pone el dedo en la llaga de uno de los problemas principales del naturalismo actual, pero eso no es suficiente para abandonar el naturalismo (al menos el metodológico), porque no hay alternativa mejor. $\mathrm{Y}$, en concreto, el teísmo (o, en la terminología que prefiere Diéguez Lucena, «sobrenaturalismo») no es una alternativa mejor, porque introducir a Dios no es explicativo, ni en ciencia, ni en filosofía.

Bien. Tratemos de decir algo sobre este planteamiento.

En primer lugar estoy (y he estado siempre) completamente de acuerdo en que algo parecido a lo que él llama naturalismo metodológico es la actitud natural —y más sensata - del científico que estudia la naturaleza.

¿Por qué escribo «algo parecido», en vez de asumir directamente la propuesta que nos ofrece? Bueno, simplemente porque, tal y como la formula Diéguez Lucena, no creo, ni que sea del todo neutral, ni que sea lo que la mayor parte de los científicos han tenido en la cabeza a lo largo de la historia de la ciencia. Repasemos su texto:

El naturalismo metodológico es la tesis que sostiene que, en el avance de nuestros conocimientos, hemos de proceder como si sólo hubiese entidades y causas naturales. Sólo las 
causas naturales y las regularidades que las gobiernan tienen auténtica capacidad explicativa. Apelar a causas o a entidades sobrenaturales [...] es lo mismo que no explicar nada.

Hasta donde conozco la historia de la ciencia, me parece que la mayor parte de los científicos, o al menos los físicos que levantaron la mayor parte del edificio de esta ciencia clave — de Galileo a Kepler, de Newton a Maxwell, de Faraday a Planck-, lo que tenían en mente era más bien el siguiente planteamiento: Dios es racional, y ha dotado por eso a la naturaleza de una profunda racionalidad, que se traduce en leyes y regularidades. De manera que nuestra labor consiste en descubrir las leyes que la racionalidad divina ha impreso en el mundo. Esto no es exactamente lo mismo que dice el párrafo citado. No se trata de proceder como si sólo hubiese entidades naturales, sino, más bien, de proceder considerando que la entidad sobrenatural por excelencia, Dios, donde se manifiesta es en las leyes de la naturaleza, cuya estabilidad y racionalidad son expresión de la fidelidad y racionalidad del Creador. Por supuesto, esto no es óbice para que buena parte de los padres de la física creyeran además en la posibilidad de intervenciones de Dios en el mundo al margen de las leyes de la naturaleza... sólo que, por su carácter extraordinario (no regular), estas intervenciones no podrían ser objeto de estudio científico. $\mathrm{Y}$, por tanto, tampoco cabría recurrir a ellas en el curso de una investigación científica: las explicaciones científicas deben ser explicaciones sobre la base de las leyes de la naturaleza.

Semejante posición (o la versión naturalista semi-equivalente) me parece que es irrenunciable a la hora de hacer ciencia. Y, por eso, no puedo menos que darle la razón a Diéguez Lucena cuando critica la propuesta de hacer una «ciencia cristiana» que incluya una manifestación de lo sobrenatural distinta 
de la que ya de por sí constituyen las leyes de la naturaleza. De hecho, en un debate sobre teísmo, materialismo y cosmología, publicado hace tres años, escribí estas palabras, que vuelvo a subrayar ahora.

[...] la advertencia de que determinados datos físico-cosmológicos concuerdan bien con la concepción teológica del universo como creación no puede sustituir a (o ponerse en el mismo plano explicativo de) las explicaciones que la física pueda dar de estos datos, en el caso de que se trate de datos susceptibles, en principio, de una explicación de este tipo. La cosmología es una parte de las ciencias físicas, y las ciencias físicas tienen un modo de ofrecer explicaciones, que consiste tanto en la construcción de modelos de los fenómenos que se estudian, con la ayuda de las teorías existentes, como también en la construción de teorías, que den cuenta del mayor número posible de modelos físicos particulares. [...] En física tenemos que buscar explicaciones físicas ${ }^{1}$.

En definitiva: no puede haber «ciencia cristiana», ni «ciencia atea», ni «ciencia aria», ni «ciencia soviética», sino ciencia a secas, que es una actividad de búsqueda de las regularidades que presenta la naturaleza, basada en la observación sistemática y (donde se pueda) en la experimentación.

Ahora bien, otra cosa muy distinta es afirmar que el naturalismo metodológico es también la actitud preferible en filosofía. De ahí que, para entender el núcleo de mi discrepancia con Diéguez Lucena, baste con reflexionar acerca de este párrafo de su artículo:

El naturalismo metodológico [...], es visto por muchos filósofos (entre los que me encuentro) como una opción saludable en la propia filosofía. El filósofo que así lo estime, tenderá a creer que no hay diferencias metodológicas que marquen una separación abso-

1 Soler, López Corredoira, 2008: 49-50. 
luta entre la filosofía y la ciencia —o si se quiere, que la filosofía también debe tomar la evidencia empírica como piedra de toque de sus propuestas teóricas, que a su vez han de interpretarse como hipótesis revisables- y, por tanto, pensará que la acción divina no sólo no es explicativa en la ciencia, sino que tampoco lo es en la filosofía. Dios (en todo caso) sería algo a explicar (y a justificar), no algo que pueda utilizarse como premisa explicativa. Desde este punto de vista, decir, como hace Plantinga, que sólo Dios garantiza la fiabilidad de nuestros conocimientos es tanto como decir que es un milagro que tengamos conocimientos fiables.

Digamos, para empezar, que entendería más que mi interlocutor sostuviera esta tesis, si sostuviera además un naturalismo epistemológico a la Quine, y aspirara, por tanto, a la resolución (disolución) definitiva de la filosofía en ciencia natural. En ese caso, sería bastante lógico que, lo mismo que en las explicaciones científicas no se recurre explícitamente a Dios (pues éste se manifiesta como el autor de las leyes de la naturaleza para el científico teísta, y el naturalista se puede quedar con esas leyes como un hecho bruto, prescidiendo de su Autor), exigiera lo propio en filosofía.

Pero Diéguez Lucena conoce muy bien los problemas del naturalismo de Quine, y, tanto en su réplica a mi artículo, como en el propio libro que sirve de base a este diálogo, se esfuerza por marcar con claridad las distancias en este punto:

En el libro arriba mencionado explico las razones por las que creo que debe rechazarse la tesis reduccionista fuerte, defendida por Quine, según la cual la epistemología debe desaparecer integrada en la psicología. Aunque simpatizo con la idea naturalista moderada de una continuidad ciencia-filosofía (lo que excluye la identidad o la sumisión de la una a la otra, o de la otra a la una), creo que la ciencia no tiene por qué contar en todos los ámbitos con la última palabra y que hay métodos no científicos de obtención de conocimiento genuino. Pero, esto es una posición personal que no hace ahora al caso. 
Bien. Yo también simpatizo abiertamente con la idea de una continuidad ciencia-filosofía, en los términos en los que la presenta Diéguez Lucena. Pero creo que lo mencionado por él en la cita anterior sí hace mucho al caso aquí. Pues, una vez que admitimos que la filosofía tiene una entidad propia, hay que reconocer que teísmo y naturalismo son, ante todo, dos marcos filosóficos alternativos básicos de entender la realidad, dos «metafísicas» (empleando este término en un sentido un tanto laxo). De manera que, así como la idea de una «ciencia cristiana» resulta por lo menos chocante, existe indudablemente una filosofía cristiana $-\mathrm{y}$, dicho sea de pasada, no pocos logros de la historia del pensamiento corren de su cuenta-. Por consiguiente, no podemos eliminar de entrada uno de estos marcos (teísta o naturalista) por motivos metodológicos.

¿Se trata, pues, por lo que se refiere a la elección entre teísmo y naturalismo, de mera cuestión de gustos? No, yo no diría eso. Más bien se trata de dos planteamientos ontológicos que pueden confrontarse. Pero no eliminando uno de ellos de entrada, con un subterfugio (ya sea metodológico, semántico, terminológico, o de otro tipo). La pista para confrontar el naturalismo y el teísmo como posiciones filosóficas acerca del modo de ser de la realidad (basada en un caso en la materia inerte, y en otro caso en una mente creadora y ordenadora), nos la ofrece el propio Diéguez Lucena al principio de su réplica:

\footnotetext{
El naturalismo es una opción filosófica (y metodológica) y, como tal, todo intento de justificación no puede aspirar a mucho más que a mostrar, frente a las alternativas disponibles, su mayor plausibilidad, dado el conocimiento de fondo, su mayor riqueza
} 
$\mathrm{Y}$ esto ya es otra cosa, efectivamente. Si uno quiere tomar una decisión acerca de si adoptar el teísmo o el naturalismo, lo que tiene que hacer es plantearse su riqueza heurística, su potencia para promover la investigación, etc. Dicho de otro modo, la simplicidad en la forma de enlazar los datos (un criterio que, entre otras cosas, favorece las explicaciones que dejan un mínimo de datos sueltos), la capacidad de acoger con naturalidad nuevos hechos, la fecundidad que resulta de poder extender una explicación hacia aspectos que no se consideraron al formularla originalmente, la solidez del entrelazamiento de los distintos aspectos de la explicación, etc., son criterios que pueden aplicarse para comparar la aceptabilidad racional del teísmo y del naturalismo como imágenes del mundo. Por eso la discusión entre metafísicas es una actividad filosófica con sentido, y la opción filosófica que uno adopte no puede reducirse a una mera cuestión de gustos.

En otros lugares ${ }^{2}$ he argumentado extensamente en favor de la tesis de que, la ciencia en general, y la física en particular, y la cosmología actual muy en particular, encajan de un modo más sencillo, atendiendo a los criterios mencionados en el párrafo anterior, en la cosmovisión teísta que en la naturalista. Este no es el momento de repetir lo escrito ahí. Pero sí de afirmar, teniendo lo anterior de fondo - es decir, teniendo en cuenta la fuerza del planteamiento filosófico teísta-, que Plantinga está en su perfecto derecho de afirmar que sólo Dios garantiza la fiabilidad de nuestros conocimientos. 
Por supuesto, Diéguez Lucena está también en su perfecto derecho de entender esta afirmación como equivalente a decir que es un milagro que tengamos conocimientos fiables. $\mathrm{Y}$ es que, en este caso, ambas afirmaciones podrían resultar, a la postre, realmente equivalentes: Sin vínculo conocido entre el contenido semántico de los estados mentales y la realidad fisicoquímica de los estados cerebrales, y sin grandes esperanzas de poder hallar un mecanismo que otorgue a estos contenidos mentales eficacia causal en el plano fisicoquímico, cuanto más subrayemos el predominio ontológico de la base físicoquímica (y esto, en el fondo, es el ideal naturalista, que no puede menos que apuntar, sugerir, preferir, o inclinar, todo lo indirectamente que se quiera, hacia el naturalismo ontológico), tanto más incierto se volverá el estatuto de lo mental. Y planteando así las cosas, ¿qué menos que un milagro podría salvar aún la epistemología?

Bien. A estas alturas de la exposición, supongo que algún lector podría preguntarse que cómo es posible que, pensando yo de este modo, esté recomendando un libro que, a fin de cuentas, lo que se propone es contribuir a la naturalización de la epistemología. Y, sin embargo, la respuesta es sencilla: Recomiendo la obra de Diéguez Lucena, en primer lugar, porque es muy seria, y da que pensar. Y, en segundo lugar, porque, leyéndola sin olvidar la problemática que subyace a la relación entre lo cerebral y lo mental, la historia evolutiva que se esboza en ella es perfectamente asumible, y de gran interés para cualquier filósofo que considere importante tener en cuenta en su reflexión los datos que provienen de las ciencias naturales. Una actitud muy sensata, con independencia de que uno sea, o no sea, naturalista. 